recommended for dealing with rupture of the urethra complicating fractures and injuries of the pelvis. The earlier writers recommend first to try to introduce a catheter into the bladder and if this succeeds to leave it as long as circumstances permit. As a matter of fact, this course is seldom practicable, for when the rupture is complete it is almost impossible to reach the bladder by simple catheterisation, the ends of the torn urethra being separated by a considerable interval. If successful at all it can only be achieved by a rigid instrument which is unsuitable for con. tinnous drainage of the bladder. What often happens when a catheter is passed is that it enters the prevesical space and as it draws off several ounces of extravasated urine which collects in that position, and as the point of the catheter is felt to lie in a free space the bladder is thought to have been successfully entered when in reality it lies full of urine behind the catheter. I have committed this error myself and seen it done several times by others. The importance of knowing this possibility is obvious. When the attempt to empty the bladder by means of the catheter has been made without success, the next step formerly advised was to make an incision in the perineum and attempt to reach the bladder by that route. If it fails, extravasated urine will soon find its way out through the perineal wound and further mischief will be prevented.

Mr. Bond, whose paper I have already quoted and who recognises clearly the position of the rupture in the urethra, recommends adding a suprapubic incision to the perineal and in some cases advises opening the bladder suprapubically and passing a drainage tube through the neck of the bladder and out at the perineal wounds. Dr. Ratherfurd ${ }^{6}$ also advises combined suprapubic and perineal drainage, together with the use of a soft catheter passed along the whole course of the urethra. Dr. Lowson ${ }^{7}$ adopted a similar procedure in his case with good result. My own practice is to rely entirely on continuous drainage of the bladder through a rubber catheter passing along the whole length of the urethra into the bladder and attached to Cathcart's suction apparatus. The advantages of draining the bladder by the natural route are obvious. In the first place, it approximates the torn ends of the ruptured tube and permits union and repair to take place under the most favourable and most rapid conditions. In the second, it is possible by this means to keep the bladder continuously empty without the escape of any urine into the wound. Cathcart's apparatus is by no means effective when attached to a tube introduced into the bladder through a suprapubic incision, because it is almost impossible to prevent the entry of air into the tube, and this greatly impair its powers of suction. But when the same apparatus is applied to a catheter introduced through the urethra this difficulty does not occur and I have found it perfectly reliable.

It may be said that, granting the advantage of draining the bladder through a catheter in the urethra, it is not always possible to introduce it. I believe that if the anatomy of the injury is correctly appreciated there will seldom be any difficulty in finding the distal end of the torn urethra through a perineal incision, which should always be the first step in dealing with these cases. I have mentioned that the bladder and prostate after the rupture, when complete, fall back on the rectum into the hollow of the sacrum. By palpation through the rectum it is easy to identify the prostate and then to bring it into the perineal wound, where the orifice of the urethra is easily seen. In the case of my own mentioned above the rupture was not complete, and the patient not having reached puberty the prostate was not easily felt. I therefore opened the bladder above the pubes, as was done also by Dr. Lowson ${ }^{8}$ in his case, and passed the catheter from behind forwards. By this means if necessary a catheter can always be introduced through the whole course of the urethra. It will be noted that in the case of the boy alluded to I completely closed the bladder in order to insure the success of the suction through the catheter. Healing of both wounds was primary and the whole convalescence was rapid and complete. A subsequent case of complete rupture with fractured pelvis treated by the same method, but without a suprapubic cystotomy, was equally satisfactory and normal micturition was resumed in three weeks.

The question of suturing the torn urethra depends on circumstances. When the rapture is complete and the torn ends are widely separated sutures should certainly be employed.
In the first place, the obvious thing to do to repair a gaping wound is to sew it up and so promote direct dealing and diminish the chance of stricture. In the second place, it is important to retain the torn ends firmly together in case it may be necessary to change the catheter. When the urethra is held together by strong supporting sutures of silkworm gut (not passing through the mucous membrane) the catheter may be removed ab the end of a week or earlier if necessary and a fresh rubber catheter introduced quite easily. When the rupture is not complete and the torn ends fall naturally together the sutures may be dispensed with.

The chief objection likely to be raised to the method I have recommended is the danger of closing a large wound which is liable to become septic. Sepsis is indeed a danger of all wounds and in urinary surgery it is peculiarly dangerous. Drainage of the pelvic wound should theretore always be provided tor by tubes or gauze wicks for the first 48 hours, or longer if necessary. Sepsis can be prevented in the great majority of cases if the same scrupulous care is exercised in urinary as in all other cases. The chief risk is that infection has already occurred before the case comes under the surgeon's care, either by neglect or by the intro. duction of a catheter without proper precautions. In a case in which the history and symptoms make an injury of the bladder or urethra probable it would be well if house surgeons or others who are first called would refrain from passing dubious instruments and leave all manipulations to be done in the operating-theatre under proper conditions. Apart from previous infection all the conditions are favourable for aseptic healing. The patients are generally healthy and young, with normal urine, which opposes no bar to primary union even if it comes for a short time in contact with the wound.

Lastly, a few words may be added on the treatment of rupture of the urethra due to direct violence in the perineum, such as kicks and straddling falls. The guiding principles are exactly the same. Aroid infection by careless catheterisation and cut down at once in the perineum whenever the passage of blood from the penis makes it certain that the urethra has been wounded. Even contusions and partial mucous lacerations are apt to be followed by stricture if not incised, drained, and where necessary repaired by sutures. When the rupture is in the membranous part, it is, as I have already pointed out, in front of the triangular ligament and in this position the rupture is easily found even when it is complete. A soft catheter should be passed into the bladder and the two ends of the urethra brought together over it by means of sutures just missing the mucous membrane. The perineal wound is then closed with the exception of a small portion drained by a gauze wick, and if the urine be drained by Cathcart's apparatus for a week, primary union of the urethra without stricture is not difficult to obtain. The method of merely passing a catheter and tying it in always leads to sepsis and is no bar whatever to the production of stricture. The method is faulty and dangerous and should be entirely abandoned.

Note.-I have omitted to refer to another published case which illustrates very clearly the difference between pelvic and perineal ruptures of the urethra-namely, "A Case of Fatal Pelvic Injury in a Child in which a Collection of Blood in the Prevesical Space simulated Distension of the Bladder," by Mr. Herbert Page.

Wolverhampton.

\section{GALL-STONES IN THE APPENDIX.}

\section{BY H. A. LEDIARD, M.D. EDIN., F.R.C.S. ENG.,} SURGEON TO THE CUMBERLAND INFIRMARY.

A MAN, aged 26 years, was admitted to the Cumberland Infirmary in April, 1906, complaining of having had two attacks of abdominal pain, diagnosed as appendicitis. The patient was very healthy up to two or three years ago, when he began to suffer occasionally from slight abdominal pain and discomfort after taking food and at times a feeling of weariness or actual pain in the lumbar region after any exertion. Two years before admission he was operated upon for inguinal hernia in this infirmary. The patient as a rule had been rather constipated and was especially so about four months before admission; for some weeks at this time he noticed that his urine was of a dark reddish colour on 
standing. About a month before admission the patient had an attack of acute pain over the whole lower abdomen lasting one day. He romited once then and had to keep to bed all day. On the next day, although he felt some slight abdominal pain and was rather weak, he went back to work again. His urine at this time was again thick and dark red in colour. He remained fairly well for a month and then seven days before admission acute abdominal pain began, mostly about the umbilicus, but later becoming more marked in the right iliac region. There were frequent vomiting for the first day, severe headache, and constipation, while tenderness and slight resistance were found over the appendix region. The pain gradually lessened and vomiting ceased, until in four days he was able to get up and on admission, three days later, there was no pain or tenderness and he was quite able to go about. At no time had the patient had pain over the liver region, in the chest or about the shoulders, nothing ever suggesting gall-stone colic, nor had jaundice or even the slightest yellow tinging of the skin or conjunctiva been noticed either by the patient or his friends. No gall-stones had ever been seen in the motions.

The abdomen was opened in the right iliac region and the appendix was exposed. Slight adhesion of the appendix to the posterior abdominal wall at one point was found: the appendix was long and had rather thickened walls. The mesentery was tied and the appendix was removed. It was found to contain some turbid mucus and 11 small stones, of varying sizes from that of a pea to that of a large pin-head. These stones were black in colour, rather soft, and faceted like gall-stones. On examination they were found to consist of cholesterin and to contain bile pigment. The patient made a good recovery and was discharged in about three weeks. For the clinical notes I am indebted to Dr. William Templeton, house surgeon in the hospital at the time.

Remarks. - The occasional presence of gall-stones in the appendix is fully established and is alluded to in general terms by modern writers of text-books. Roberts, ${ }^{1}$ for example, remarks "that they cause trouble by lodging in the vermiform appendix." As far back as 1871 it was a recognised fact that gall-stones were liable to be arrested in the appendix, ${ }^{2}$ but Murchison, in writing on the same subject, expressed a doubt if the concretions were not intestinal rather than biliary. ${ }^{3}$ That the occurrence is not exactly frequent may be gathered from Naunyn who in 1892 wrote ${ }^{3}$ : "It has happened that a gall-stone has made its way into the vermiform appendix, the result of which accident may be perityphlitis and fatal peritonitis." Naunyn mentions Budd's case, quoted also by Murchison, in which a gall-stone in the vermiform appendix caused perforation and fatal peritonitis. The same author mentions cases of a similar kind by Trousseau, Sirey, Rehn, Treves, and Wegeler. In Wegeler's case the supposed gall-stone was by chemical analysis proved to consist of fæcal matter. Mistakes of this kind might easily arise if the appearance only of the concretion was relied upon; if, however, a concretion was faceted and had a chink-like sound when allowed to fall on a hard surface such as a marble slab, it would probably ke a gall-stone, but chemical analysis will always remain as the true test to determine the source of a concretion in the appendix.

As a general rule the size of stones met with in the gallbladder or separated from fæcal discharge is too large to enter the canal of the appendix, and the same is true for the stones of fruit, formerly supposed to get into the appendix; the stercolith having simulated an orange pip or a damson stone. Here again a chemical analysis would effectually serve to get rid of a fiction which has been repeated in all books and is still believed in by some. What I suggest is that all concretions found in or near the appendix, or in an abscess or otherwise, should be systematically examined by section and by analysis in order to settle definitely whether a concretion is a stercolith or a gall-stone, covered or not by fæcal deposit. On one occasion a hair was imbedded in a stercolith from an operation I performed lately, and a similar experience fell to Mr. W. H. Battle. ${ }^{5}$ The hair was possibly the nucleus on which the concretion formed, and in the

1 Roberts: Theory and Practice of Medicine, vol. ii., p. 846, tenth edition, 1905 .

2 J. Russell Reynolds : System of Medicine, vol. iii., p. 314.

3 Clinical Lectures on Diseases of the Liver, third edition, 1885, p. 551 . 4 B. Naungn : A Treatise on Chol

5 Descriptive Catologue, Pathological Specimens, Mruseum of the Royal College of Surgeons of England, 1905, Appendix xix., second edition, p. 14. Fo. $2559 \mathrm{C}$ same way a gall-stone or some other foreign body migh become a nucleus. Treves ${ }^{6}$ has written that mischief in the appendix may be due to a foreign body, such as a pin, a grape pip, a small shot, a piece of bone, and the like. "Most of the so-called cherry-stones," he writes, " and datestones found in the appendix are calcareous concretions mixed with fæcal matter."

A good example of fæcal calculus was removed lately in the course of an appendix operation; it shows that a seed has formed the nucleus and around it are layers of inspissated faces and the whole is impregnated with lime salts. By the courtesy of $\mathrm{Mr}$. D. Prain, director of the Royal Botanic Gardens, Kew, this concretion was examined by Mr. L. A. Boodle, F.L.S., assistant in the Jodrell Laboratory in the garden. The nucleus was compared with practically all the objects that might conceivably be met with in such a situation-grape or raisin, gooseberry, currant, and other small seeds of fruits generally consumed-but it did not agree in the least with any of them. But with the fruitlet, or " pip," of a fig it agreed so absolutely in size, general appearance, and structure that, in the opinion of $\mathrm{Mr}$. Boodle, the nucleus of my concretion could be accepted with hardly any hesitation as coming from the fig.

Concretions can sometimes be felt in the appendix through the abdominal wall without the aid of an anæsthetic, the favourable condition being a relaxed state of the muscles and a moderately thin paries. In the case recorded these gall-stones were actually felt, not all but some, and in consequence of the presence of concretions the operation was done, although the condition of the patient seemed absolutely healthy. There cannot be much doubt that these gall-stones would have perforated sooner or later.

The pathological association of gall-stones in the gallbladder and appendicitis, to which attention has been drawn, is hardly an established doctrine and may be merely a coincidence, although 35 per cent. of Ochsner's patients operated on for gall-stones had suffered from appendicitis.? Strange indeed it would be if destructive lesions in the appendix by infecting the blood in the portal system were among the causes of the formation of gall-stones and that gall-stones might find their visit a return one to the appendix. The whole question is dealt with by Moynihan. A death from perforation of the appendix by a gall-stone is recorded by Mayo Robson in THE LANCET of Dec. 29th, 1906, p. 1768.

Carlisle.

\section{PNEUMOTHORAX FROM PUNCTURE OF} THE PLEURA.

By J. C. F. D. VAUGHAN, M.R.C.S. ENG., L.R.C.P. LOND.,

LATE HOUSE SURGEON, ST, THOMAS'S HOSPITAL AND EAST LONDON HOSPITAL FOR CHILDREN.

As pneumothorax is an uncommon condition and stab wounds are, fortunately, also not common, at least, in Fngland, I thought the following case might be of interest. I was at the time surgeon on a well-known line to the East and the vessel under my charge was running down the Red Sea with a shade temperature of $104^{\circ} \mathrm{F}$. , when one evening the native barber ( $\mathrm{my}$ interpreter and go-between with the native crew) came and reported that one coolasie (lascar sailor) had stabbed another in the back with a clasp knife having a three-inch blade. It was then about 8.30 o'clcck on the evening of July 21st, and on walking aft I found a well-built lascar, about 24 years of age, with a terrified face lying in a pool of blood surrounded by a curious ring of squatting natives.

On examination the patient had an anxious expression, his respirations being very rapid, shallow, and thoracic in nature, his chest being in a position of full inspiration, especially on the left side, which looked almost blown up. There was a clean-cut incised wound three-quarters of an inch long in the back between the eighth and ninth rib and two and a half inches from the mid-line, which was perfectly clean and had stopped bleeding, the loss of blood having been unimportant. There was no surgical emphysema. The pulse was rather feeble and rapid, the patient evidently

6 Treves on Appendicitis, System of Surgery, vol. ii., p. 625, 1896. 7 Annals of Surgery, vol. Xxxv, p. 708 . Quoted by Moynihan 